\title{
Secondhand smoke exposure and asthma outcomes among African-American and Latino children with asthma
}

\author{
Andreas M Neophytou, ${ }^{1}$ Sam S Oh, ${ }^{2}$ Marquitta J White, ${ }^{2}$ Angel C Y Mak, ${ }^{2}$ Donglei Hu, ${ }^{2}$ \\ Scott Huntsman, ${ }^{2}$ Celeste Eng, ${ }^{2}$ Denise Serebrisky, ${ }^{3}$ Luisa N Borrell, ${ }^{4}$ Harold J Farber, ${ }^{5}$ \\ Kelley Meade, ${ }^{6}$ Adam Davis, ${ }^{6}$ Pedro C Avila, ${ }^{7}$ Shannon M Thyne, ${ }^{8}$ \\ William Rodríguez-Cintrón, ${ }^{9}$ José R Rodríguez-Santana, ${ }^{10}$ Rajesh Kumar, ${ }^{11,12}$ \\ Emerita Brigino-Buenaventura, ${ }^{13}$ Saunak Sen, ${ }^{14}$ Michael A Lenoir, ${ }^{15}$ \\ L Keoki Williams, ${ }^{16,17}$ Neal L Benowitz, ${ }^{2}$ John R Balmes, ${ }^{1,2}$ Ellen A Eisen, ${ }^{1}$ \\ Esteban G Burchard ${ }^{2}$
}

- Additional material is published online only. To view please visit the journal online (http://dx.doi.org/10.1136/ thoraxjnl-2017-211383).

For numbered affiliations see end of article.

\section{Correspondence to} Dr Andreas M Neophytou, Division of Environmental Health Sciences, School of Public Health, University of California, Berkeley, Berkeley, CA 94720 USA; aneophytou@berkeley.edu

Received 7 December 2017 Revised 29 March 2018 Accepted 8 May 2018 Published Online First 13 June 2018

\section{Linked}

- http://dx.doi.org/10.1136/ thoraxjnl-2018-212071

Check for updates

To cite: Neophytou AM, Oh SS, White MJ, et al. Thorax 2018;73:1041-1048.

\section{ABSTRACT}

Background Secondhand smoke (SHS) exposures have been linked to asthma-related outcomes but quantitative dose-responses using biomarkers of exposure have not been widely reported.

Objectives Assess dose-response relationships between plasma cotinine-determined SHS exposure and asthma outcomes in minority children, a vulnerable population exposed to higher levels of SHS and underrepresented in the literature.

Methods We performed analyses in 1172 Latino and African-American children with asthma from the mainland USA and Puerto Rico. We used logistic regression to assess relationships of cotinine levels $\geq 0.05 \mathrm{ng} / \mathrm{mL}$ with asthma exacerbations (defined as asthma-related hospitalisations, emergency room visits or oral steroid prescription) in the previous year and asthma control. The shape of dose-response relationships was assessed using a continuous exposure variable in generalised additive logistic models with penalised splines.

Results The OR for experiencing asthma exacerbations in the previous year for cotinine levels $\geq 0.05 \mathrm{ng} / \mathrm{mL}$, compared with $<0.05 \mathrm{ng} / \mathrm{mL}$, was $1.40(95 \% \mathrm{Cl} 1.03$ to 1.89), while the $O R$ for poor asthma control was 1.53 (95\% Cl 1.12 to 2.13). Analyses for dose-response relationships indicated increasing odds of asthma outcomes related with increasing exposure, even at cotinine levels associated with light SHS exposures. Conclusions Exposure to SHS was associated with higher odds of asthma exacerbations and having poorly controlled asthma with an increasing dose-response even at low levels of exposure. Our results support the conclusion that there are no safe levels of SHS exposures.

\section{INTRODUCTION}

Exposure to secondhand smoke (SHS) has been linked to multiple adverse health effects, including cardiovascular disease and respiratory diseases such as lung cancer and asthma. ${ }^{1-4}$ Despite public health awareness efforts including legislation aimed at protecting non-smokers from SHS exposure, and

\section{Key messages}

What is the key question?

- This study aims to assess the shape of the dose-response relationship between secondhand smoke exposures as measured by plasma cotinine and asthma outcomes, in minority children with asthma.

What is the bottom line?

- Our results suggest an increase in odds of asthma exacerbations and poor asthma control with increasing exposure, even at levels associated with light secondhand smoke exposures.

Why read on?

- We provide a quantitative dose-response assessment of the relationship between secondhand smoke exposure and asthma outcomes in a vulnerable population that is understudied in the respiratory health literature.

an overall decreasing trend in exposures, SHS exposure remains a prevalent risk factor worldwide, contributing to a large portion of overall disease burden and mortality in adults and children. ${ }^{4-7}$ In the USA, more than $40 \%$ of children aged 3-11 are estimated to be exposed to some SHS. ${ }^{7}$ Disparities exist in the prevalence of SHS exposures based on race/ethnicity and socioeconomic status, with non-Hispanic blacks and those living in poverty being more likely to be exposed. ${ }^{7-9}$ Under-represented populations are also more burdened by asthma in the USA, with higher prevalence of asthma morbidity and mortality in African Americans and Puerto Ricans compared with European Americans. ${ }^{1011}$ SHS exposure is linked with asthma exacerbations, poor asthma control and increased asthma symptoms among children with asthma. ${ }^{12-17}$

Objective measures of SHS exposures in epidemiological studies rely on biochemical testing for assessment of tobacco smoke, which usually focus 
on metabolites of nicotine, one of the major constituents of tobacco smoke and the primary determinant of addiction to tobacco products. ${ }^{18}$ Quantitative dose-response relationships between SHS exposure and asthma outcomes using biomarkers of exposure, however, are not widely reported in the literature. Furthermore, quantification of exposure using nicotine metabolites may be further complicated by race/ethnicity. Nicotine is metabolised at different rates by different racial/ethnic groups, with African Americans on average metabolising nicotine at a slower rate compared with European Americans, while smaller or not significant differences between Latinos and European Americans are reported. ${ }^{19-22}$ Higher measured levels of cotinine, the nicotine metabolite most commonly used to assess nicotine exposure, observed in African Americans ${ }^{23}$ may be the result of higher tobacco smoke exposures and slower metabolism and clearance. ${ }^{24}$ It is therefore possible that race/ethnicity specific differences in nicotine metabolism may also lead to perceived differences of dose-response by race/ethnicity that are not necessarily due to differential susceptibility to exposure effects.

In this study we examined the relationship of SHS exposure as measured by plasma cotinine, the primary proximate metabolite of nicotine, with exacerbations and disease control in African-American and Latino children with asthma. Our analyses included a quantitative assessment of dose-response between levels of plasma cotinine and odds of asthma outcomes.

\section{METHODS}

\section{Study population}

The study is based on subsamples of participants from the Gene-environments and Admixture in Latino Americans (GALA II) study and the Study of African Americans, Asthma, Genes and Environments (SAGE II) from whom plasma cotinine data were available. GALA II and SAGE II are described in detail elsewhere. ${ }^{25}$ Briefly, GALA II and SAGE II are parallel case-control studies of asthma conducted among Latino and African-American children, respectively. GALA II recruited Latinos from five regions (Chicago, IL; Bronx, NY; Houston, TX; San Francisco Bay Area, CA; and Puerto Rico) and SAGE II recruited African Americans from the San Francisco Bay Area only. Participants whose parents identified as Latino or African American (or self-identified as Latino or African American if 18 or older), and had four Latino or African-American grandparents, were recruited for the two studies, respectively. Additionally, participants were 8-21 years old, aiming to ensure a homogenous case population among those who were old enough to perform spirometry, as lung function was one of the outcomes considered in the parent studies. Pregnant women in their third trimester were excluded, because the progression of their pregnancy would have interfered with lung function measurements. Additional exclusion criteria included a history of lung or chronic diseases other than asthma, and current smokers, or those with at least 10 pack-years smoking history. Asthma cases were defined as subjects with a physician diagnosis of asthma, plus two or more symptoms of coughing, wheezing or shortness of breath in the past 2 years. The current study was restricted to a subsample of 1208 asthma cases, selected for cotinine analysis as part of a separately funded study. Online supplementary table S1 summarises demographic characteristics in the selected 1208 cases and the total number cases from the two parent studies.

\section{Outcomes and covariates}

Asthma exacerbations and asthma control were the primary outcomes of interest and were assessed based on information collected through questionnaires administered in person with the children's parents/caretakers by trained bilingual (EnglishSpanish) interviewers, or the participants themselves if they were 18 or older. Asthma exacerbations in the previous year were defined as any asthma-related hospitalisation or emergency room (ER) visit, or prescription of oral steroids for asthma during the 12 months prior to recruitment. Each of (1) asthma-related hospitalisations, (2) asthma-related ER visits and (3) prescription of oral steroids, as well as a combined category of all three types of exacerbations were assessed as separate measures of the outcome. Asthma control was classified according to National Heart, Lung and Blood Institute measures ${ }^{26}$ into three categories: controlled, not well controlled and very poorly controlled asthma. Relationships between 'controlled' asthma as a referent category compared with 'not well controlled' and 'very poorly controlled' as a combined category, as well as each of the 'not well controlled' and 'very poorly controlled' categories to 'controlled' asthma were assessed separately.

Measures of demographic information (including maternal education and whether the family had health insurance), medical histories and environmental exposures were collected through the questionnaires. Information was also collected on maternal smoking during pregnancy, as well as current smoking habits of both parents in the house, other smokers in the house and total number of current smokers in the household.

\section{Cotinine and nicotine metabolite ratio}

Blood samples from participating children were collected at baseline at the same time as questionnaire administration. Samples from participants in the current study were analysed for the nicotine metabolites cotinine and 3-hydroxycotinine (3HC) by liquid chromatography-tandem mass spectrometry. ${ }^{27}$ The lower limit of quantitation (LOQ) for this assay depends on the volume of plasma available. The volumes available in our study ranged from 0.1 to $1.0 \mathrm{~mL}$, with the LOQ ranging from 0.2 to $0.02 \mathrm{ng} / \mathrm{mL}$, respectively. The LOQ was $0.05 \mathrm{ng} / \mathrm{mL}$ or less for $1112(92.1 \%)$ of the samples. Participants with plasma cotinine levels $>10 \mathrm{ng} / \mathrm{mL}(\mathrm{n}=36)$ were considered to be active smokers ${ }^{28}$ and excluded from the analyses for the relationships between SHS exposure and asthma outcomes resulting in a final sample of 1172 participants. Figure 1 illustrates participant inclusion from each of the parent studies, GALA II and SAGE II, resulting in an analytical sample of 1172 .

A binary exposure variable was created with subjects deemed exposed to SHS if plasma cotinine levels were above $0.05 \mathrm{ng} /$ $\mathrm{mL}$, or above the LOQ if that was higher than $0.05 \mathrm{ng} / \mathrm{mL}$, and otherwise unexposed. In a previous study using National Health and Nutrition Examination Survey data, cotinine concentrations less than $0.05 \mathrm{ng} / \mathrm{mL}$ were deemed to result from not being recently been exposed to SHS, or to have been exposed at low levels that the exposure could not be detected. ${ }^{28}$ A continuous exposure variable (log transformed) was used in analyses for dose-response, with subjects without quantitative measures assigned the sample LOQ. The nicotine metabolite ratio (NMR), the ratio of $3 \mathrm{HC}$ and cotinine, is an indicator of enzymatic activity of the liver enzyme CYP2A6, which is primarily responsible for nicotine metabolism. ${ }^{23}$ Higher NMR is correlated with higher rate of nicotine metabolism. NMR values were available only in participants with both cotinine and $3 \mathrm{HC}$ levels measured above the LOQ $(n=421$, of which 372 had plasma cotinine $<10 \mathrm{ng} / \mathrm{mL}$ ). 


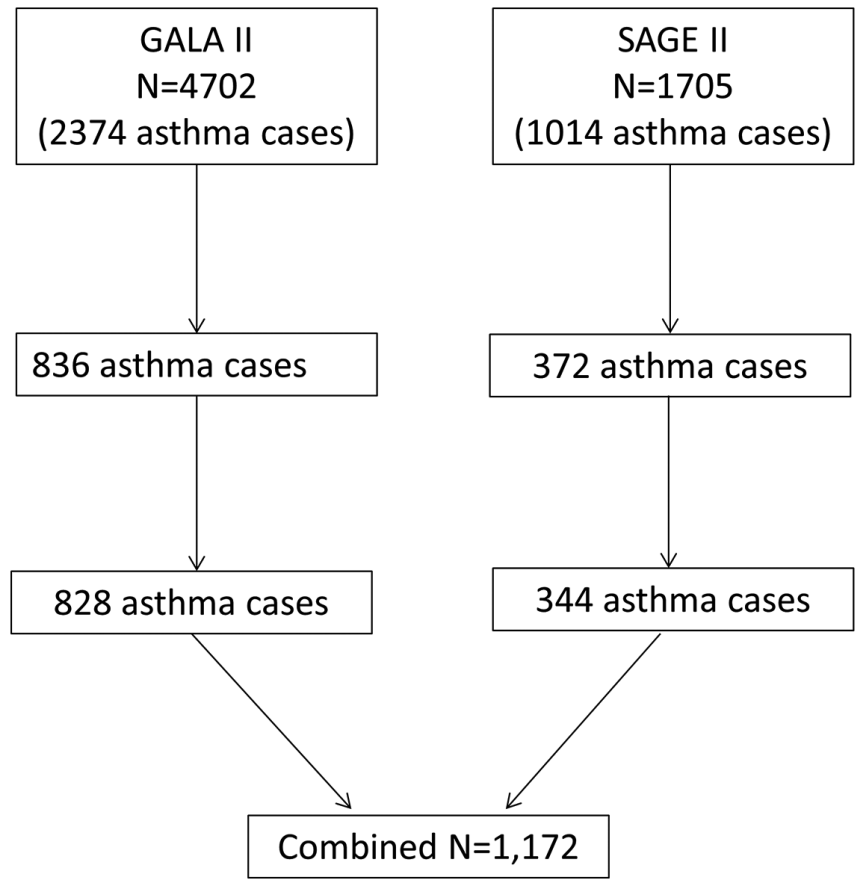

\section{Original Parent studies}

\section{Participant subsamples with plasma cotinine assessment}

\section{Exclusion of active smokers} (plasma cotinine $\geq 10 \mathrm{ng} / \mathrm{mL}$ )

\section{Final analysis sample}

Figure 1 Flow chart illustrating participant inclusion from the two parent studies (GALA II \& SAGE II) in the current study. GALA, Geneenvironments and Admixture in Latino Americans; SAGE, Study of African Americans, Asthma, Genes and Environments.

\section{Statistical analyses}

We assessed associations of self-reported SHS exposure (any current smokers reported in the household vs none) and cotinine-assessed SHS exposure with asthma outcomes. Associations between binary cotinine exposure and asthma exacerbations in the previous year were examined using logistic regression models (separate models for asthma-related hospitalisations, asthma-related ER visits, oral steroid prescription and any of the three exacerbations combined). Logistic regression was also used to assess associations between binary cotinine and asthma control using 'controlled' asthma as reference compared with those with 'not well controlled' and 'very poorly controlled' in a combined category. We also applied multinomial logistic regression comparing each of the 'not well controlled' and 'very poorly controlled' categories with 'controlled' asthma separately. All of the models included age, sex, race/ethnicity, recruitment region, an indicator variable for self-reported maternal smoking during pregnancy, a categorical variable for maternal education (less than high school, high school or equivalent, at least some college) and an indicator variable for whether the family had health insurance. We also considered NMR as a covariate using 50 imputed data sets to account for missing NMR values in models for the entire study sample as well as stratified by parent study, as a proxy for racial/ethnic group. Multiple imputation was implemented using multivariate imputation by chained equations. $^{29}$

Quantitative dose-response relationships between continuous cotinine levels and each of the above outcomes were assessed in generalised additive models, extensions of generalised linear models in which the linear predictors depend on smoothing functions of predictors such as spline functions. ${ }^{30}$ We used penalised spline terms for the effect of cotinine levels. We also fitted generalised additive models including an interaction term between exposure and an indicator variable for parent study (GALA II vs SAGE II, as a proxy for racial/ethnic group). ${ }^{31}$ All analyses were carried out using R software (V.3.3.3, R Development Core Team, Vienna, Austria).

\section{RESULTS}

Demographic characteristics for the study sample in question are summarised in table 1 . Briefly, mean \pm SD deviation age was $13.1 \pm 3.4$, and $53 \%$ of participants were male with similar distribution of sex between participants from GALA II and SAGE II.

Figure 2 illustrates plasma cotinine distributions by race/ ethnicity among those with plasma cotinine measured above the sample LOQ. African Americans had higher cotinine levels compared with Latinos, (respective mean \pm SD of $0.51 \pm 1.41$ and $0.20 \pm 0.58$, two-sample $\mathrm{t}$-test $\mathrm{p}=0.00013$, with sample LOQ assigned to participants without levels measured above the LOQ). There was an increasing trend of plasma cotinine levels with reported number of current smokers in the household, though 315 of 777 (41\%) participants with no current smokers reported in the household had measured levels of cotinine above $0.05 \mathrm{ng} / \mathrm{mL}$ (or the LOQ if higher than $0.05 \mathrm{ng} / \mathrm{mL}$ ). Summary statistics on plasma cotinine levels, overall and by self-reported number of smokers in household are presented in table 2 .

Table 3 summarises results for the associations between binary variables of self-reported (presence of any current smokers in the household) and biomarker-based (binary cut-off of $0.05 \mathrm{ng} /$ $\mathrm{mL}$ or LOQ if higher than $0.05 \mathrm{ng} / \mathrm{mL}$ ) measures of SHS exposure and asthma outcomes. Associations between self-report of any current smoker in the household and asthma exacerbation variables were not strong, but self-reported exposures were associated with increased odds of uncontrolled asthma with the OR comparing 'very poorly controlled' with 'controlled' asthma reaching statistical significance (OR: 1.79, 95\% CI 1.18 to 2.70). Exposure to any SHS determined by plasma cotinine levels above $0.05 \mathrm{ng} / \mathrm{mL}$ (or LOQ if higher than $0.05 \mathrm{ng} / \mathrm{mL}$ ) was positively associated with all asthma outcomes. Although not 
Table 1 Demographic characteristics in a sample of 1208 Latino and African-American children with asthma, from the GALA II $(n=836)$ and SAGE II $(n=372)$ parent studies, recruited between 2006 and 2011

\begin{tabular}{|c|c|c|}
\hline Characteristic & $\begin{array}{l}\text { GALA II } \\
\mathrm{n}(\%)\end{array}$ & $\begin{array}{l}\text { SAGE II } \\
\mathrm{n}(\%)\end{array}$ \\
\hline Age (mean (SD)) & $13.1(3.4)$ & $13.1(3.4)$ \\
\hline Male & $442(52.9)$ & $201(54.0)$ \\
\hline \multicolumn{3}{|l|}{ Race/ethnicity } \\
\hline Mexican & $157(18.8)$ & - \\
\hline Other Latino & $15(1.8)$ & - \\
\hline Puerto Rican & 664 (79.4) & - \\
\hline African American & - & $372(100)$ \\
\hline \multicolumn{3}{|l|}{ Maternal education } \\
\hline Fifth grade or less & $25(3.0)$ & $0(0)$ \\
\hline Grades 6-11 & $183(22.0)$ & $18(4.9)$ \\
\hline High school graduate or equivalent & $223(26.8)$ & $103(28.1)$ \\
\hline At least some college & $401(48.2)$ & $245(66.9)$ \\
\hline Health insurance & $806(97.2)$ & $369(99.2)$ \\
\hline $\begin{array}{l}\text { Any current smokers reported in } \\
\text { household* }\end{array}$ & $159(23.4)$ & $99(26.6)$ \\
\hline \multicolumn{3}{|l|}{ Recruitment region } \\
\hline Chicago & $74(8.9)$ & - \\
\hline Houston & $34(4.1)$ & - \\
\hline New York & $81(9.7)$ & - \\
\hline Puerto Rico & $598(71.5)$ & - \\
\hline SF Bay Area & $49(8.9)$ & $372(100)$ \\
\hline \multicolumn{3}{|l|}{ Asthma controlt } \\
\hline Controlled & $132(19.4)$ & $123(33.1)$ \\
\hline Not well controlled & $265(39.1)$ & $106(28.5)$ \\
\hline Very poorly controlled & $281(41.4)$ & $143(38.4)$ \\
\hline \multicolumn{3}{|c|}{ Asthma exacerbations in the past 12 months $t$} \\
\hline Hospitalisations & $92(11.1)$ & $8(2.2)$ \\
\hline ER visits & $478(58.3)$ & $112(31.2)$ \\
\hline Oral steroid prescription & $370(44.7)$ & $62(17.0)$ \\
\hline
\end{tabular}

Percentages for variables with missingness are based on the totals with complete data.

*Self-reported number of current smokers in the household is limited to 679 of the GALA II subjects.

†Asthma control was available for 678 of the GALA II subjects due to missingness in the information required for the variable definition. Information on asthma exacerbations was available in 1182, 1179 and 1192 subjects, respectively, for hospitalisations, ER visits and oral steroid prescription.

$E R$, emergency room; GALA, Gene-environments and Admixture in Latino Americans; SAGE, Study of African Americans, Asthma, Genes and Environments; SF, San Francisco.

always statistically significant, associations for asthma exacerbations were above the null for all definitions, but stronger and statistically significant for oral steroid prescriptions which seem to be driving the overall association. Analyses adjusting for NMR using multiple imputed data sets yielded similar estimates, with an OR for experiencing asthma exacerbations in the previous year for cotinine levels $\geq 0.05 \mathrm{ng} / \mathrm{mL}$, compared with $<0.05 \mathrm{ng} /$ $\mathrm{mL}$ of 1.37 (1.01-1.87). ORs for asthma control were 1.41 (0.99-2.00) for 'not well controlled' versus 'controlled' asthma and $1.82(1.28-2.59)$ for 'very poorly controlled' versus 'controlled' asthma.
Quantitative dose-response relationships between continuous plasma cotinine levels and asthma exacerbations are presented in figure 3, and relationships for asthma control are presented in figure 4. An increasing dose-response was observed for asthma exacerbations over the range of cotinine levels though $\mathrm{p}$ values for the overall null hypothesis for the smoothing terms were not statistically significant. Increasing dose-response was observed for asthma control when comparing 'very poorly controlled' with 'controlled', with a steeper increase at lower levels of exposure and a plateauing effect at higher levels $(p=0.024)$, but no apparent dose-response was seen when comparing 'not well controlled' with 'controlled'. The OR comparing 'very poorly controlled' with 'controlled' asthma was 1.68 (95\% CI 1.16 to 2.43 ) for an increase in exposure from $0.05 \mathrm{ng} / \mathrm{mL}$ (used as cut-off for unexposed) to $1 \mathrm{ng} / \mathrm{mL}$ (considered indicative of minor to moderate SHS exposures). ${ }^{28}$

Effect estimates by study for a binary exposure by study from multiply imputed data sets for NMR are depicted in table 4. Using a binary exposure cut-off, effect estimates for asthma control appeared stronger in African-American children compared with Latino children, but the same was not true for asthma exacerbations. Quantitative dose-response relationships by study from models using penalised splines are illustrated in online supplementary figure $\mathrm{S} 1$.

\section{DISCUSSION}

We observed increased odds of asthma exacerbations as well as increased odds of having poorly controlled asthma among African-American and Latino children associated with SHS exposures determined by plasma cotinine levels. We also observed suggestive dose-response relationships even at lower exposure concentrations. To our knowledge, such quantitative doseresponse relationships between SHS exposure measured using plasma cotinine levels and asthma outcomes have not been previously reported in the literature. The relative increase in odds of adverse asthma outcomes with increasing exposure, especially concerning poor asthma control, was steeper at the lower range of exposures, with large increases in odds of adverse outcomes reached even at levels of cotinine associated with only minor SHS exposures $(0-1 \mathrm{ng} / \mathrm{mL}) .^{28}$ These findings suggest that even low levels of SHS exposure can result in adverse asthma-related effects, further supporting the guidelines stating that there are no safe levels of SHS exposure. ${ }^{4}$

Associations between asthma outcomes in children and SHS exposure have been reported in the literature with exposures associated with increased risk of asthma, asthma exacerbations, wheezing and reduced lung function. ${ }^{4141617}$ Tobacco smoke is a mixture of compounds, including carbon and nitrogen oxides, particulate matter, nitrosamines, polycyclic aromatic hydrocarbons, carbonyls and other chemicals, many of which are known toxicants that can induce inflammation and altered immune responses. ${ }^{32}$ We observed associations between SHS exposure and increased odds of poor asthma control, which appeared stronger in African-American children compared with Latino children, but associations with asthma exacerbations were more similar by race/ethnicity. Findings of differences in the strengths of the cotinine-asthma outcome relationships by race/ethnicity may indicate a difference in susceptibility, but should be interpreted with caution as metabolic rates of cotinine differ by race/ ethnicity. ${ }^{28} 33$ Given the observed metabolic differences, cotinine levels in African Americans may result from lower external exposure to tobacco smoke than the same levels in populations that metabolise nicotine at faster rates. ${ }^{24}$ Measured cotinine in 


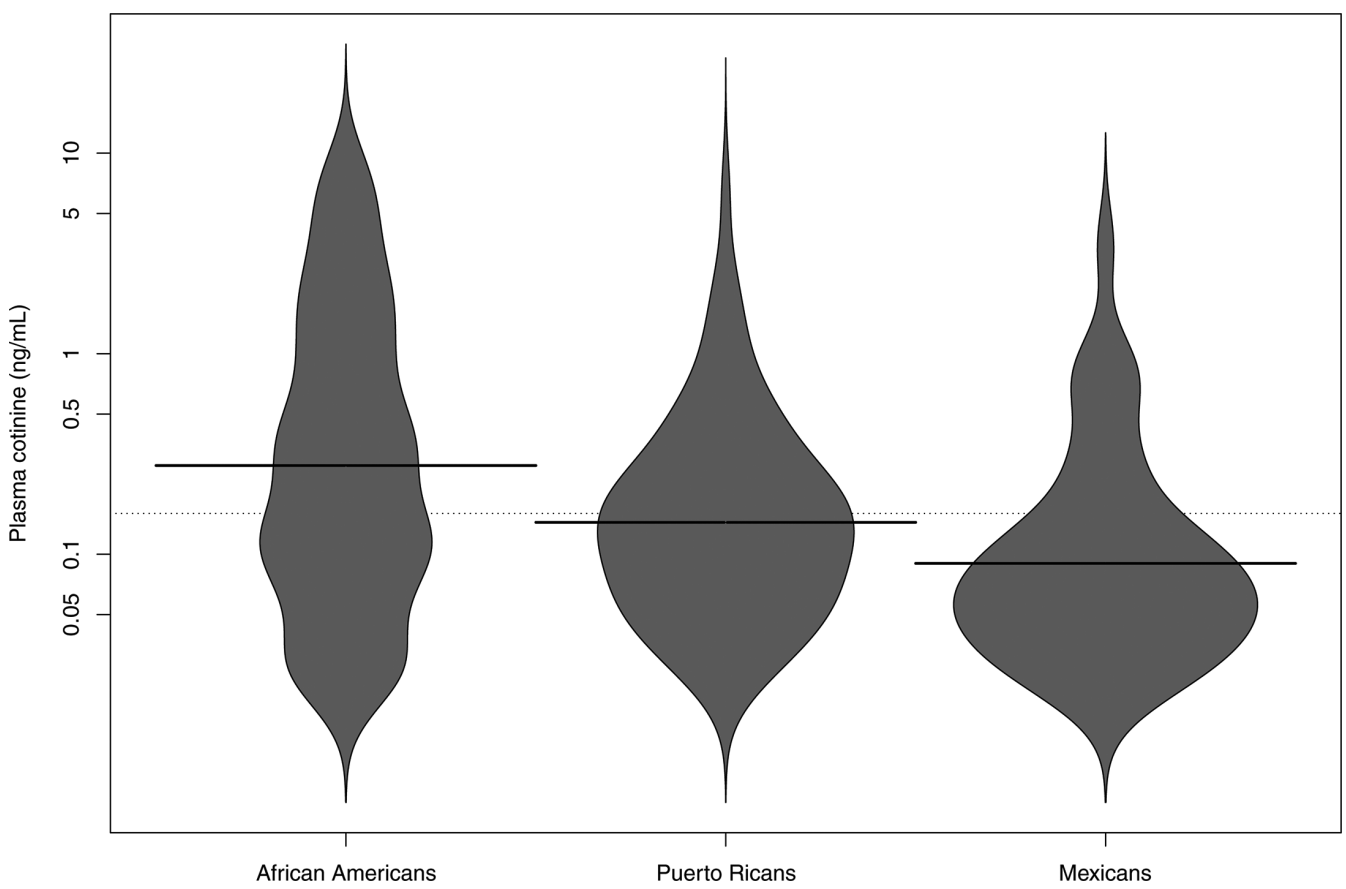

Figure 2 Beanplots for plasma cotinine levels by race/ethnicity. The shapes of the beans represent density traces for the respective distributions in each group, mirrored on the vertical axis. Solid lines represent the group-specific median values, while the dotted line represents the overall median value.

African Americans may therefore not necessarily be as representative of higher exposure to other tobacco smoke constituents. Additionally, asthma control is a composite outcome based on asthma symptoms, pulmonary function, history of exacerbations (including ER visits) and medication use, ${ }^{26}$ all of which may carry racial/ethnic differences as well. For example, while African Americans and Mexican Americans have established reference equations for pulmonary function based on a representative sample of the US population, ${ }^{34}$ the same is not true for Puerto Ricans. ${ }^{35-38}$ Misclassification of the outcome is more likely to occur in populations without dedicated prediction equations.

Self-reported measures of SHS exposure did not show good specificity when compared with measures of plasma cotinine. Approximately $41 \%$ of children whose parents reported no active smokers in the house had detectable levels of plasma cotinine, though mean levels of plasma cotinine did increase with increasing numbers of smokers reported in the household. This is consistent with previous findings and with SHS exposure being under-reported when relying on self-reported data, particularly in the case of exposures happening outside the

Table 2 Summary statistics for plasma cotinine levels, overall and by self-reported number of smokers in the household (participants without measured cotinine levels above the LOQ were assigned the sample LOQ)

\begin{tabular}{ll}
\hline Participants by self-reported SHS & $\begin{array}{l}\text { Median plasma cotinine and IQR }(\mathrm{ng} / \\
\mathrm{mL})\end{array}$ \\
\hline Overall $(\mathrm{n}=1172)$ & $0.05(0.02,0.17)$ \\
\hline Current smokers in the household* & \\
\hline $0(n=777)$ & $0.03(0.02,0.12)$ \\
$1(n=181)$ & $0.14(0.04,0.42)$ \\
$\geq 2(n=58)$ & $0.28(0.08,0.99)$ \\
\hline
\end{tabular}

*Data restricted to 1016 participants with self-reported SHS exposure data. LOQ, lower limit of quantitation; SHS, secondhand smoke. home, which would not be captured by the self-reported assessment in the current study. ${ }^{16} 39-41$ Thirdhand smoke exposures are also likely to be unaccounted by self-reported measures, but may contribute to measured cotinine concentrations and lead to adverse effects. $^{42}$

Biochemical assessment of SHS exposure allows for more objective characterisation of tobacco smoke exposure and epidemiologic assessment of exposure-outcome relationships unburdened by exposure misclassification bias seen in self-reported measures of exposure. Plasma cotinine, the biomarker used to determine exposure in the current study, is the major proximate

Table 3 Associations between SHS exposure (defined using selfreport and measured plasma cotinine $(>0.05 \mathrm{ng} / \mathrm{mL}$ or above the limit of quantification if higher than $0.05 \mathrm{ng} / \mathrm{mL}$ )) and asthma outcomes

\begin{tabular}{|c|c|c|}
\hline \multirow[b]{2}{*}{ Asthma outcomes } & \multicolumn{2}{|l|}{ OR $(95 \% \mathrm{Cl})$} \\
\hline & $\begin{array}{l}\text { Self-reported } \\
\text { exposure* }\end{array}$ & $\begin{array}{l}\text { Plasma cotinine } \\
\text { determined } \\
\text { exposure }\end{array}$ \\
\hline $\begin{array}{l}\text { Asthma exacerbations in the previous } \\
12 \text { monthst }\end{array}$ & $1.08(0.75$ to 1.57$)$ & 1.40 (1.03 to 1.89$)$ \\
\hline Hospitalisations & 1.77 (0.79 to 3.95$)$ & 1.26 (0.60 to 2.67$)$ \\
\hline ER visits & $1.21(0.70$ to 2.09$)$ & $1.07(0.65$ to 1.75$)$ \\
\hline Oral steroid prescription & $1.00(0.71$ to 1.41$)$ & 1.54 (1.18 to 2.04$)$ \\
\hline Asthma control (binary outcome)‡ & 1.62 (1.09 to 2.38$)$ & 1.53 (1.12 to 2.13$)$ \\
\hline Not well controlled versus controlled & $1.43(0.93$ to 2.21$)$ & 1.39 (0.98 to 1.98$)$ \\
\hline Very poorly controlled versus controlled & 1.79 (1.18 to 2.70$)$ & $1.67(1.18$ to 2.36$)$ \\
\hline \multicolumn{3}{|c|}{$\begin{array}{l}\text { *Self-reported exposure to SHS was determined as any versus no reported current } \\
\text { smokers in the household. } \\
\text { †Asthma exacerbations assessed as a combined variable for any exacerbations } \\
\text { (hospitalisations, ER visits, prescription of oral steroids) versus none. } \\
\text { †Asthma control assessed as binary outcome with a combined 'not well controlled' } \\
\text { and 'very poorly controlled' category compared with controlled asthma. } \\
\text { ER, emergency room; SHS, secondhand smoke. }\end{array}$} \\
\hline
\end{tabular}



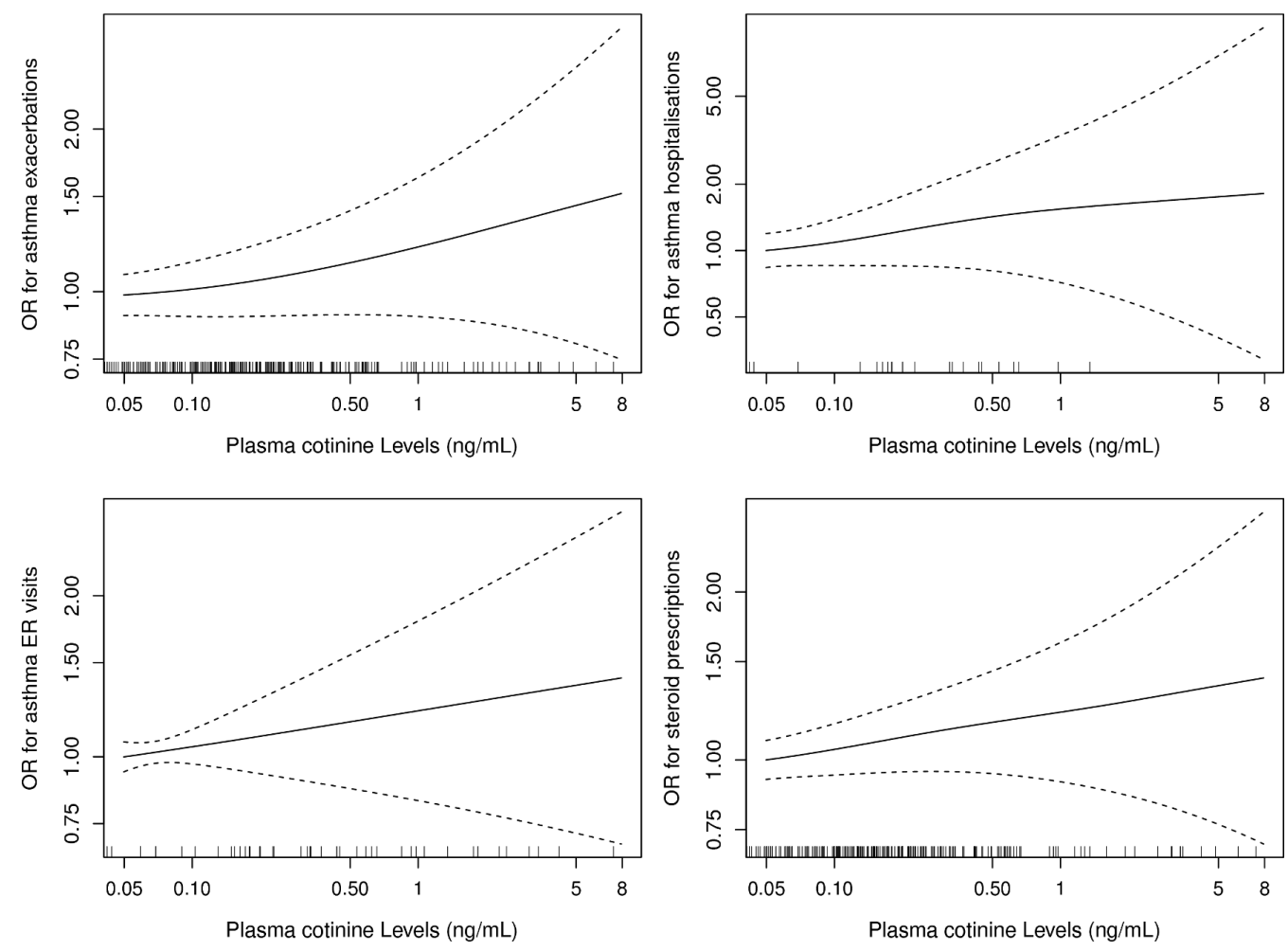

Figure 3 Dose-response of plasma cotinine and asthma exacerbations in the past 12 months, from generalised additive models using penalised splines. Results presented for total asthma exacerbations and separately for asthma-related hospitalisations, asthma-related ER visits and prescription of oral steroids for asthma. ER, emergency room.
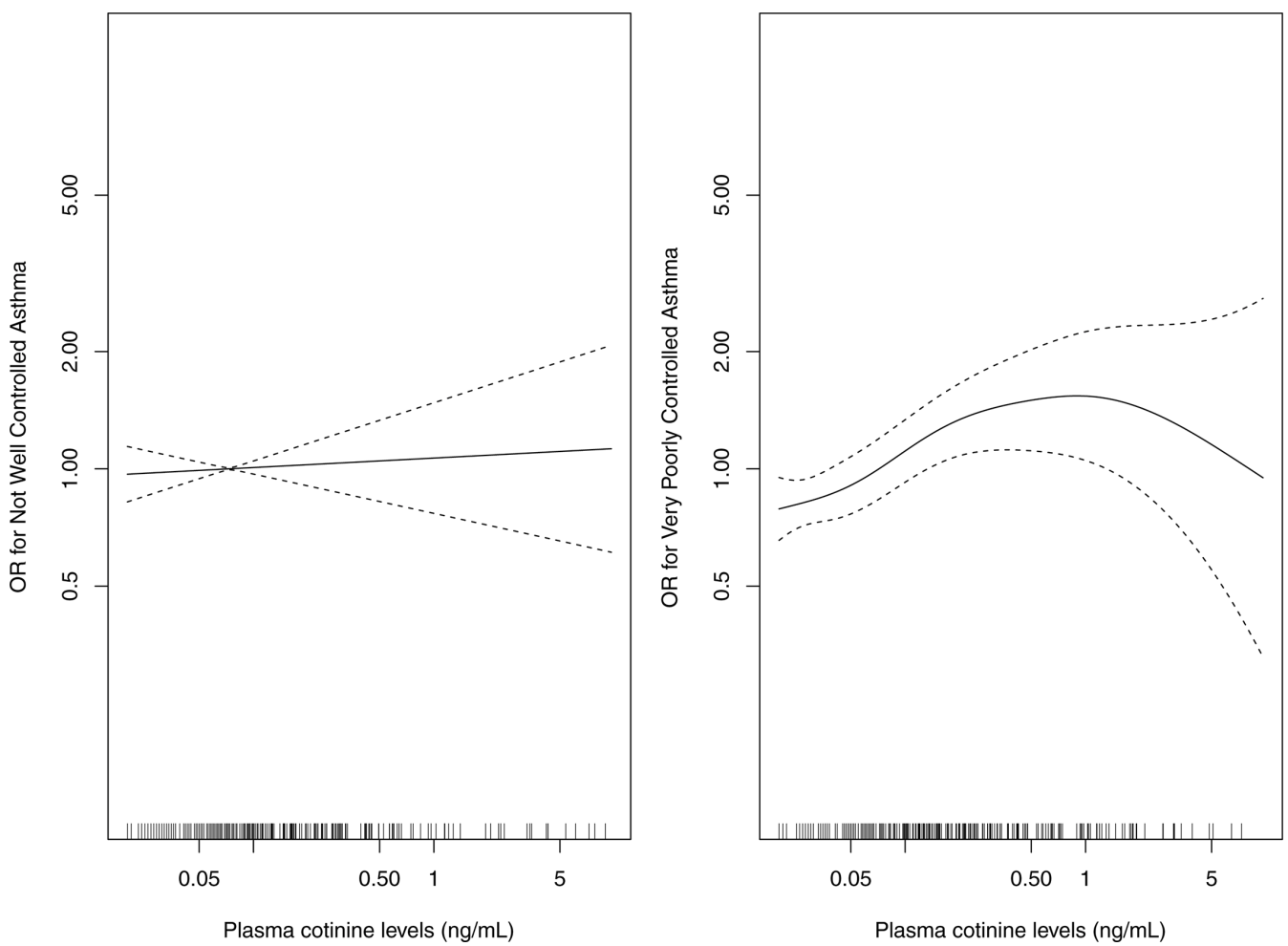

Figure 4 Dose-response of plasma cotinine and asthma control, from generalised additive models using penalised splines. Results presented comparing each of 'not well controlled' and 'very poorly controlled' with 'controlled' asthma separately.

metabolite of nicotine and has been considered a reliable, objective measure of SHS exposure for some time. ${ }^{43}$ Nicotine and its metabolites, however, are not necessarily causative agents of the adverse effects of tobacco smoke examined in this study, with effects most likely driven by other compounds as described above. 
Table 4 Associations between SHS exposure (defined as measured plasma cotinine $>0.05 \mathrm{ng} / \mathrm{mL}$ or above the limit of quantification if higher than $0.05 \mathrm{ng} / \mathrm{mL}$ ) and asthma outcomes by study (as proxy for race/ethnicity) using multiple imputation data to account for missing NMR values

\begin{tabular}{lll}
\hline & \multicolumn{2}{l}{ OR $(95 \% \mathrm{Cl})$} \\
\cline { 2 - 3 } & \multicolumn{2}{l}{ Study } \\
\cline { 2 - 3 } Asthma outcomes & GALA II & SAGE II \\
\hline $\begin{array}{l}\text { Asthma exacerbations in the previous } \\
\text { 12 months* }\end{array}$ & $1.38(0.95$ to 2.01$)$ & 1.27 (0.74 to 2.19$)$ \\
\hline Asthma control (binary outcome) $\dagger$ & $1.27(0.84$ to 1.91$)$ & $2.16(1.27$ to 3.67$)$ \\
\hline Not well controlled versus controlled & $1.21(0.66$ to 2.22$)$ & $1.58(0.87$ to 2.91$)$ \\
\hline Very poorly controlled versus controlled & $1.33(0.80$ to 2.22$)$ & $2.77(1.51$ to 5.00$)$ \\
\hline
\end{tabular}

*Asthma exacerbations assessed as a combined variable for any exacerbations (hospitalisations, ER visits, prescription of oral steroids) versus none.

†Asthma control assessed as binary outcome with a combined 'not well controlled' and 'very poorly controlled' category compared with controlled asthma.

ER, emergency room; GALA, Gene-environments and Admixture in Latino

Americans; NMR, nicotine metabolite ratio; SAGE, Study of African Americans,

Asthma, Genes and Environments; SHS, secondhand smoke.

The data in the current study are based on a subsample of cases from two parent case-control studies. Outcomes in the parent studies were assessed based on retrospective self-reported data (potentially leading to overestimation or underestimation of some of the outcomes), while the exposure was only quantified in one point in time. The plateauing effect observed at analyses of dose-response at higher exposures may represent a true exposure-response function, but also could be the result of less stable functions due to the scarce data at higher ranges of exposure (also evidenced by the less stable CIs at higher exposures), or due to reverse causation as parents of children with worse asthma may be more likely to reduce their children's exposures. The binary definition of exposure using a cut-off may have also led to misclassification, especially in samples with LOQ greater than the cut-off. However, this misclassification is expected to be entirely non-differential with respect to the outcomes, and would likely produce an underestimate of the true effect size.

The cross-sectional nature of the data did not allow us to address possible limitations such as these potential issues of reverse causation. Although point prevalence measures of cotinine are useful for assessing recent and ongoing SHS exposure ${ }^{44}$ a longitudinal study with prospective outcome assessment as well as biomarker exposure assessed at multiple time points would be better equipped to address these issues. Furthermore, analyses with interactions were underpowered and we did not examine for effects within separate categories for the different Latino groups.

Strengths of the study include information obtained through use of a detailed questionnaire on potential confounding factors including indicators of socioeconomic status, and the relatively large sample size for an understudied study population, composed of Latino and African-American children. There is a lack of minority representation in asthma-related research, ${ }^{45}$ despite these populations being disproportionately affected by asthma morbidity and SHS exposure.

In summary, we demonstrated increasing odds of asthma exacerbations and poorer asthma control with increasing levels of SHS exposure measured with plasma cotinine levels in children from under-represented populations. This pattern of dose-response was seen within the range of cotinine levels indicative of light SHS exposure, suggesting no safe levels of SHS exposure. Differences in exposure levels were also observed by race/ethnicity.

\section{Author affiliations}

${ }^{1}$ Division of Environmental Health Sciences, School of Public Health, University of California, Berkeley, Berkeley, California, USA

${ }^{2}$ Department of Medicine, University of California, San Francisco, San Francisco, California, USA

${ }^{3}$ Pediatric Pulmonary Division, Jacobi Medical Center, Bronx, New York, USA

${ }^{4}$ Department of Epidemiology and Biostatistics, Graduate School of Public Health and

Health Policy, City University of New York, New York City, New York, USA

${ }^{5}$ Department of Pediatrics, Baylor College of Medicine, Texas Children's Hospital,

Houston, Texas, USA

${ }^{6}$ Department of Pediatrics, Children's Hospital and Research Center, Oakland, California, USA

${ }^{7}$ Feinberg School of Medicine, Northwestern University, Chicago, Illinois, USA

${ }^{8}$ Department of Pediatrics, David Geffen School of Medicine, University of California, Los Angeles, Los Angeles, California, USA

${ }^{9}$ Veterans Caribbean Health Care System, San Juan, Puerto Rico

${ }^{10}$ Centro de Neumología Pediátrica, San Juan, Puerto Rico

${ }^{11}$ Division of Allergy and Immunology, Feinberg School of Medicine, Northwestern

University, Chicago, Illinois, USA

${ }^{12}$ Ann \& Robert H Lurie Children's Hospital of Chicago, Chicago, Illinois, USA

${ }^{13}$ Department of Allergy and Immunology, Kaiser Permanente-Vallejo Medical Center, Vallejo, California, USA

${ }^{14}$ Department of Preventive Medicine, University of Tennessee Health Science Center, Memphis, Tennessee, USA

${ }^{15}$ Bay Area Pediatrics, Oakland, California, USA

${ }^{16}$ Department of Internal Medicine, Henry Ford Health System, Detroit, Michigan, USA

${ }^{17}$ Center for Health Policy and Health Services Research, Henry Ford Health System, Detroit, Michigan, USA

Acknowledgements We thank Polly Cheung for performing cotinine analyses.

Contributors $\mathrm{AMN}$ was responsible for data analyses and manuscript preparation with input from SSO, MW, AM, NLB, JRB, EAE and EGB. DH and SH performed statistical analyses. CE, DS, LNB, EBB, HJF, KM, AD, PCA, SMT, WRC, JRRS, SS, MAL, LKW, RK and EGB participated in the design and coordination of the initial study. All coauthors contributed to interpretation of results, and provided revisions and approval of the final manuscript.

Funding This study was supported in part by the Sandler Family Foundation, the American Asthma Foundation, the RWJF Amos Medical Faculty Development Program, Harry Wm and Diana V Hind Distinguished Professor in Pharmaceutical Sciences II, the Tobacco-Related Disease Research Program under Award No 24RT-0025, a grant by the Flight Attendants Medical Research Institute (FAMRI), and the following institutes of the National Institutes of Health: National Heart Lung and Blood Institute (NHLBI) 1R01HL117004, R01HI128439, R01HL135156, 1X01HL134589, R01HL118267; National Institute of Environmental Health Sciences (NIEHS) R01ES015794, R21ES24844, K99ES027511; the National Institute on Minority Health and Health Disparities (NIMHD) 1P60MD006902, U54MD009523, 1R01MD010443; and National Institute of Allergy and Infectious Diseases (NIAID) R01Al079139.

Competing interests None declared.

Patient consent Not required.

Ethics approval University of California, San Francisco.

Provenance and peer review Not commissioned; externally peer reviewed.

(c) Article author(s) (or their employer(s) unless otherwise stated in the text of the article) 2018. All rights reserved. No commercial use is permitted unless otherwise expressly granted.

\section{REFERENCES}

1 Hackshaw AK, Law MR, Wald NJ. The accumulated evidence on lung cancer and environmental tobacco smoke. BMJ 1997;315:980-8.

2 Barnoya J, Glantz SA. Cardiovascular effects of secondhand smoke: nearly as large as smoking. Circulation 2005;111:2684-98.

3 Eisner MD. Secondhand smoke and obstructive lung disease: a causal effect? Am J Respir Crit Care Med 2009;179:973-4.

4. US Department of Health and Human Services. The Health Consequences of Smoking - 50 Years of Progress. A Report of the Surgeon General. Atlanta, GA: US Department of Health and Human Services, Centers for Disease Control and Prevention, National Center for Chronic Disease Prevention and Health Promotion, Office on Smoking and Health, 2014. 
5 Öberg M, Jaakkola MS, Prüss-Üstün A, et al. Second-hand smoke. Assessing the burden of disease at national and local levels. (WHO Environmental Burden of Disease Series, No. 18), 2010.

6 Oberg M, Jaakkola MS, Woodward A, et al. Worldwide burden of disease from exposure to second-hand smoke: a retrospective analysis of data from 192 countries. Lancet 2011:377:139-46.

7 Centers for Disease Control and Prevention (CDC). Vital signs: nonsmokers' exposure to secondhand smoke - United States, 1999-2008. MMWR Surveill Summ 2010;59:1141-6.

8 Kit BK, Simon AE, Brody DJ, et al. US prevalence and trends in tobacco smoke exposure among children and adolescents with asthma. Pediatrics 2013;131:407-14.

9 Homa DM, Neff LJ, King BA, et al. Vital signs: disparities in nonsmokers' exposure to secondhand smoke--United States, 1999-2012. MMWR Morb Mortal Wkly Rep 2015:64:103-8

10 Akinbami LJ, Moorman JE, Bailey C, et al. Trends in asthma prevalence, health care use, and mortality in the United States, 2001-2010. NCHS Data Brief 2012:1-8.

11 Barr RG, Avilés-Santa L, Davis SM, et al. Pulmonary disease and age at immigration among hispanics. results from the hispanic community health study/study of Latinos. Am J Respir Crit Care Med 2016;193:386-95.

12 Jaakkola JJK, Jaakkola MS. Effects of environmental tobacco smoke on the respiratory health of children. Scand J Work Environ Heal 2002;28:71-83.

13 Oh SS, Tcheurekdjian H, Roth LA, et al. Effect of secondhand smoke on asthma control among black and Latino children. J Allergy Clin Immunol 2012;129:1478-83.

14 Gilliland FD, Li YF, Peters JM. Effects of maternal smoking during pregnancy and environmental tobacco smoke on asthma and wheezing in children. Am J Respir Crit Care Med 2001;163:429-36.

15 Strachan DP, Cook DG. Health effects of passive smoking. 6. Parental smoking and childhood asthma: Iongitudinal and case-control studies. Thorax 1998;53:204-12.

16 Chilmonczyk BA, Salmun LM, Megathlin KN, et al. Association between exposure to environmental tobacco smoke and exacerbations of asthma in children. $N$ Engl J Med 1993:328:1665-9.

17 Burke H, Leonardi-Bee J, Hashim A, et al. Prenatal and passive smoke exposure and incidence of asthma and wheeze: systematic review and meta-analysis. Pediatrics 2012;129:735-44

18 Benowitz NL. Nicotine addiction. N Engl J Med 2010:362:2295-303.

19 Benowitz NL, Perez-Stable EJ, Fong I, et al. Ethnic differences in N-glucuronidation of nicotine and cotinine. J Pharmacol Exp Ther 1999:291:1196-203.

20 Pérez-Stable EJ, Herrera B, Jacob P, et al. Nicotine metabolism and intake in black and white smokers. JAMA 1998:280:152.

21 Benowitz NL, Pérez-Stable EJ, Herrera B, et al. Slower metabolism and reduced intake of nicotine from cigarette smoking in Chinese-Americans. J Natl Cancer Inst 2002;94:108-15.

22 Wang H, Park SL, Stram DO, et al. Associations between genetic ancestries and nicotine metabolism biomarkers in the multiethnic cohort study. Am J Epidemiol 2015:182:945-51.

23 Dempsey DA, Meyers MJ, Oh SS, Ss O, et al. Determination of tobacco smoke exposure by plasma cotinine levels in infants and children attending urban public hospital clinics. Arch Pediatr Adolesc Med 2012;166:851.

24 Zhu AZ, Renner CC, Hatsukami DK, et al. The ability of plasma cotinine to predict nicotine and carcinogen exposure is altered by differences in CYP2A6: the influence of genetics, race, and sex. Cancer Epidemiol Biomarkers Prev 2013:22:708-18.

25 Nishimura KK, Galanter JM, Roth LA, et al. Early-life air pollution and asthma risk in minority children. The GALA II and SAGE II studies. Am J Respir Crit Care Med 2013;188:309-18.
26 National Asthma Education and Prevention Program (National Heart Lung and Blood Institute). Expert Panel Report 3: Guidelines for the diagnosis and management of asthma: full report 2007. Bethesda, MD, 2007.

27 Jacob III P, Yu L, Duan M, et al. Determination of the nicotine metabolites cotinine and trans-3'-hydroxycotinine in biologic fluids of smokers and non-smokers using liquid chromatography-tandem mass spectrometry: Biomarkers for tobacco smoke exposure and for phenotyping cytochrome P450 2A6 activity. Journal of Chromatography B 2011:879:267-76.

28 Benowitz NL, Bernert JT, Caraballo RS, et al. Optimal serum cotinine levels for distinguishing cigarette smokers and nonsmokers within different racial/ethnic groups in the United States between 1999 and 2004. Am J Epidemiol 2009;169:236-48.

29 .van BS, Groothuis-Oudshoorn K. mice : Multivariate Imputation by Chained Equations in R. J Stat Softw 2011.

30 Wood SN. Generalized additive models: an introduction with R. Boca Raton, FL: Chapman \& Hall/CRC, 2006

31 Coull BA, Ruppert D, Wand MP. Simple incorporation of interactions into additive models. Biometrics 2001:57:539-45.

32 US Department of Health and Human Services. The health consequences of involuntary exposure to tobacco smoke: a report of the surgeon general. Washington, DC, 2006.

33 Benowitz NL, Dains KM, Dempsey D, et al. Racial differences in the relationship between number of cigarettes smoked and nicotine and carcinogen exposure. Nicotine Tob Res 2011;13:772-83.

34 Hankinson JL, Odencrantz JR, Fedan KB. Spirometric reference values from a sample of the general U.S. population. Am J Respir Crit Care Med 1999;159:179-87.

35 Hankinson JL, Kawut SM, Shahar E, et al. Performance of American Thoracic Societyrecommended spirometry reference values in a multiethnic sample of adults: the multi-ethnic study of atherosclerosis (MESA) lung study. Chest 2010;137:138-45.

36 Pino-Yanes $M$, Thakur N, Gignoux CR, et al. Genetic ancestry influences asthma susceptibility and lung function among Latinos. J Allergy Clin Immunol 2015;135:228-35

37 Brehm JM, Acosta-Pérez E, Klei L, et al. African ancestry and lung function in Puerto Rican children. J Allergy Clin Immunol 2012;129:1484-90.

38 Kumar R, Seibold MA, Aldrich MC, et al. Genetic ancestry in lung-function predictions N Eng/ J Med 2010:363:321-30.

39 Eisner MD, Klein J, Hammond SK, et al. Directly measured second hand smoke exposure and asthma health outcomes. Thorax 2005:60:814-21.

40 Arheart KL, Lee DJ, Fleming LE, et al. Accuracy of self-reported smoking and secondhand smoke exposure in the US workforce: the National Health and Nutrition Examination Surveys. J Occup Environ Med 2008;50:1414-20.

41 Max W, Sung HY, Shi Y. Who is exposed to secondhand smoke? Self-reported and serum cotinine measured exposure in the U.S., 1999-2006. Int J Environ Res Public Health 2009;6:1633-48.

42 Matt GE, Quintana PJ, Destaillats H, et al. Thirdhand tobacco smoke: emerging evidence and arguments for a multidisciplinary research agenda. Environ Health Perspect 2011;119:1218-26.

43 Benowitz NL. Biomarkers of environmental tobacco smoke exposure. Environ Health Perspect 1999:107(Suppl 2):349-55.

44 US Department of Health and Human Services. Children and secondhand smoke exposure. Excerpts from the health consequences of involuntary exposure to tobacco smoke: a report of the surgeon general. Atlanta, GA: US Department of Health and Human Services, Centers for Disease Control and Prevention, National Center for Chronic Disease Prevention and Health Promotion, 2007.

45 Burchard EG, Oh SS, Foreman MG, et al. Moving toward true inclusion of racial/ethnic minorities in federally funded studies. A key step for achieving respiratory health equality in the United States. Am J Respir Crit Care Med 2015;191:514-21. 